Representative and explicitly clear authorities of EU Member States have agreed a 'Common Position' on F2P games, which takes a similar approach to the ASA's guidance. On 16 July it was announced that Google had agreed to adopt a broad approach to compliance with this by ceasing to describe any app on its Play store as 'free' if it contained IAPs.

It seems that the safest practice for developers going forward will be to ensure that:

- adverts for F2P products should be representative of the experience of a player who has not paid to enhance the gameplay; and

- if a game does offer players IAPs that alter gameplay, this is made explicitly clear in any advertisements that describe the game as 'free' or 'F2P'.

In addition to this new CAP guidance, anyone developing or publishing online and app-based games should familiarize themselves with the OFT's Principles on the subject (http://bit.ly/1o6BYiv). As of the dissolution of the OFT in April 2014, these were adopted by the Competition and Markets Authority and reflect the regulator's views on which practices are on the right or the wrong side of consumer laws.

Thomas Spanyol, associate, Osborne Clarke, London

\section{Facebook changes its Platform Policy in respect of in-game purchases and incentivizing page 'likes'}

\section{Ben Dunham}

Journal of Direct, Data and Digital Marketing Practice (2014) 16, 131-132. doi:10.1057/dddmp.2014.67

Who: Facebook, Inc. (Facebook)

When: 7 August 2014

Where: Worldwide

Law stated as at: 9 September 2014

\section{What happened}

New API policies

On 7 August, Facebook released a new version of its Application Platform Interface (API) and, along with it, made a few changes to its Platform Policies, which govern how developers can use their apps on the Facebook platform. 
The policy has been updated in two respects:

1. Transparency on in-app charges: The first change requires games that include mandatory or optional in-app charges to make it clear that this is the case in the app's description. This is to give people a clear indication before they start playing that the game may charge them during gameplay. The model whereby players can purchase additional lives, tokens or credits to enhance their gameplay or their chances of success is common. In particular, the 'freemium' pricing strategy has been popular among developers, whereby the initial gameplay is free of charge, but upgrades or extra in-game content comes at a monetary cost. Models incorporating in-game payments will still be permitted, but only insofar as there is upfront clarity that these payments may be required. This is a clear signal that Facebook is pushing for consumer transparency when it comes to paid-for content.

2. No additional incentive to 'like': The second change prohibits incentivizing Facebook users to use social plug-ins or to 'like' a Facebook page. Incentivizing in this context means offering awards or prizes to Facebook users who like a brand's page, or gating apps or any app content based on whether or not a Facebook user has liked a page. It should be noted, however, that Facebook has specifically acknowledged that it remains acceptable to incentivize people to log in to an app, check in at a place or enter a promotion on the brand's page. Many brands currently roll out Facebook promotions where liking their page is a requirement of entry. Under the new policy, this is no longer possible. Facebook's statement says that 'to ensure quality connections and help businesses reach the people who matter to them, we want people to like Pages because they want to connect and hear from the business, not because of artificial incentives'.

\section{Adapt or be penalized}

\section{Wider impact of changes}

\section{Why this matters}

The changes were effective as of 5 November 2014. As such, brands and app developers will have to ensure that their offerings or promotions adapt in such a way that they comply with the new Platform Policy, or risk being penalized by Facebook.

With regard to the first change, this should merely be a case of developers refining app descriptions to make clear the potential for in-app charges. The second change may have a slightly wider impact. It is obvious that Facebook wants 'likes' to reflect genuine popularity of brands or apps, rather than merely the number of Facebook users keen to get their hands on a prize who have no further interest in the page. However, marketers will now no longer be able to rely on the appeal of like-based promotions or access to exclusive Facebook content through 'app-gating' as a way to engage with Facebook users on a longer-term basis. These have both been powerful marketing tools for years, but now brands will have to think of ways to drum up popularity and generate page 'likes' without offering additional incentives to Facebook users.

Ben Dunham, associate, Osborne Clarke, London 